\title{
Legislative Responses to the Challenge of Insufficient Data on Water Service Delivery in South African Cities
}

\author{
Nicolene Renske Steyn ${ }^{1}$ (D)
}

Accepted: 10 December 2021 / Published online: 30 January 2022

(c) The Author(s), under exclusive licence to Springer Nature B.V. 2021

\begin{abstract}
This article investigates the existing legal responses to the challenge of insufficient data on water service delivery in cities. The article finds that no explicit duty exists for cities to collect the data or information that they are regularly required to provide. While such a duty may be implied from Sect. 69 of the Water Services Act 108 of 1997, there is no clear indication of what information cities would need to provide. Furthermore, an extensive analysis of the current national systems of information operated by the Department of Water and Sanitation reveals that there are numerous and significant issues on these databases, especially concerning the quality, integrity, and timeliness of the data. Finally, the article proposes that due to the unique position of cities concerning the provision of water services, and the need for complete and reliable data, the law should emphasise cities' role in the collection of data.
\end{abstract}

Keywords Legal responses · Data · Cities · South Africa - Water service delivery · Challenges

\section{Introduction}

Access to data is fundamental to assessing the status quo of water provision in cities and in the country at large. Accurately determining whether persons have access to water is necessary since the Constitution of the Republic of South Africa, 1996 (Constitution) ensures that everyone has a right to have access to sufficient water. While the state is required to take reasonable legislative and other measures to safeguard the realisation of this right, cities (referred to interchangeably as local governments or municipalities) are placed at the fore-front in this regard. In terms of the Constitution, it is an object of local government to provide services to communities

Nicolene Renske Steyn

Nicolene.Steyn@nwu.ac.za

1 South African Research Chair in Cities, Law and Environmental Sustainability, the Faculty of Law of the North-West University, Potchefstroom, South Africa 
sustainably, and water services provision is a function of local government (Constitution, Sect. 152(1)(b); Schedule 4 Part B).

However, in South Africa, the Department of Water and Sanitation (DWS) is the executive branch of the national government that is directly responsible for, amongst other aspects, the collection and assessment of water data (Water Services Act 108 of 1997, Sects. 67-70). Most of the country's water legislation speaks to the DWS' duties to collect reliable data on, for instance, the status of the country's water resources, and water supply and demand. ${ }^{1}$ The Strategic Framework for Water Services 2003 (SFWS) states that the Department will manage information to be used for monitoring, support, regulation, and planning (SFWS, p. 21). Other national government departments have a general responsibility to support the DWS as the water services sector leader in fulfilling its information management roles (SFWS, p. 21).

According to the DWS's National Water and Sanitation Master Plan 2020a (Master Plan): 'Reliable data, information and knowledge on the status of the country's water resources, water supply and sanitation are required to understand and enable spatial and non-spatial analysis and presentation of water use and water demand' (Master Plan, Volume 1 p. 43). The National Water Resource Strategy (2013) (NWRS) provides that the DWS requires access to complete and reliable information to efficaciously execute its data-related duties (NWRS, p. 63). A 2019 study on South Africa's monitoring and reporting of water supply goals and targets indicates that national data sources are available that report on the drinking water supply services in the country (Water Research Commission 2019a, p. 12). The latter data sources include the annual Statistics South Africa General Household Survey, the Statistics South Africa Census conducted every 5 years, and the Blue Drop System. Nevertheless, gaps exist in these national data sources, especially concerning the sustainability or continued supply of water services (Water Research Commission 2019a, p. 22). Furthermore, there is a lack of city-level data on the water services they provide (Bauer 2020). For example, strategies such as the Water Quality Regulation Strategy 2009 rely on the data submitted by local governments in the country, yet in some cases $63 \%$ of municipalities could not report on whether they meet drinking water quality standards or not (Masindi \& Dunker, 2016).

Factors such as persistent population growth, accelerating urbanisation, climateinduced water stresses, and changing lifestyles (Dos Santos 2017) all require of cities to become involved in monitoring and reporting on critical issues such as access to water through water services provision, particularly due to their aforementioned constitutional objective. Additionally, the Free Basic Water Implementation Strategy of 2007, for instance, places a duty on local governments (referred to as water services authorities) to provide regular feedback on the implementation of free basic water to the contemporaneous Department of Water Affairs and Forestry, now known as the DWS (Free Basic Water Implementation Strategy 2007, p. 29). Thus, effective data and information management are integral for the successful regulation and provision of water services and resources (Master Plan, Volume 1 p. 44).

\footnotetext{
${ }^{1}$ See para 3 below.
} 
If South African cities have insufficient water service delivery-related data, their ability to provide water services adequately may be affected. Moreover, it is doubtful whether legislative duties on cities exist to collect data of good quality and integrity on the water services they provide to communities. ${ }^{2}$ As such, there is a so-called persistent weak monitoring system in the water services sector (see Master Plan, Volume 1 pp. 43-44; Parliamentary Monitoring Group 2017; Masindi \& Dunker, 2016; Water Research Commission 2019b p. 195).

This article seeks to investigate the existing legal responses (if any) to the challenge of insufficient data on water service delivery in cities. The legislative responses referred to in this instance are understood as laws, policies, strategies, and plans, amongst other instruments, including legal duties, that respond to the challenge of insufficient data on water service delivery in cities. The article will commence by investigating the need for data on water service delivery in cities, followed by an analysis of the current legislative responses. Next, the article will critically reflect on the DWS' national information system and the subsequent National Water Services Knowledge System (NWSKS) with the aim to determine the current success of the DWS' adherence to its duty to collect data and monitor the water provision services in the country. This includes the correlative duty on cities to provide information on their water service provision activities on request to the DWS. From this, the article argues that a need exists for the development of enforceable duties on cities to collect data of good quality and integrity. ${ }^{3}$ The latter is necessary for improving the DWS' monitoring of water services in the country, while ensuring that cities have access to sufficient data on the water services they provide.

\section{The Need for Data on Water Service Delivery}

Cities' domains are becoming increasingly interconnected and their processes exceedingly dynamic. As such, they will require data to realise their ability to respond adequately to the challenges of service delivery, especially in the age of urbanisation and the need for sustainability (Bibri, 2018). Data are essential not only for the technological opportunities that they present, such as Big Data analytics and context-aware computing (Bibri, 2018), but also for the prospect of increased knowledge. Data allow cities to understand where they fail and succeed in terms of service delivery, determine where inequalities persist, and provide for adequate and informed decision-making, amongst many other advantages (Thakuriah et al., 2017). As the saying goes, what gets measured, gets managed; conversely, what does not get measured, does not get managed effectively (Adams, 2019).

Not everything that 'gets measured' has value. Data must be of good quality and should have the integrity to be valuable (DAMA UK Working Group, 2013; Kleppner, 2010). While there is no universal agreement, data quality generally has six

\footnotetext{
2 See para 3 below.

3 See para 2 below.
} 
dimensions, namely completeness, ${ }^{4}$ uniqueness, ${ }^{5}$ timeliness, ${ }^{6}$ validity, ${ }^{7}$ accuracy, ${ }^{8}$ and consistency ${ }^{9}$ (DAMA UK Working Group, 2013). Data integrity is known as an uncompromising adherence to certain ethical values, complete avoidance of deception, and strict honesty, as well as the state of being complete and whole, or entirely unimpaired (Kleppner, 2010). Thus, to be convinced of the integrity of data, one needs to be confident that it is complete, unaltered, and verified (Kleppner, 2010). Considering these requirements in the ensuing discussion will be necessary to determine accurately whether cities have sufficient data regarding their water supply and services, including data on leakages, working infrastructure, and the number of consumers, amongst other concerns. Notably, this article may, throughout, refer to 'information' rather than data, since processed data constitute information, and the term 'information' is more frequently referenced in South African water law (Steyn, 2020).

While cities face the challenge of insufficient data concerning the water services they provide, it is unfortunately not an isolated issue. This is because poor data affect most, if not all, actions taken by cities in the course of fulfilling their mandates. The latter includes planning and decision-making, budgeting and allocation of funds, and capacity (Master Plan p. 44). Data also play into, for instance, the challenge of the sustainability of water service delivery, since the proper maintenance and operation of water infrastructure require an accurate depiction of its current state, management, and performance, amongst other factors (Rural Water Supply Network 2010). Failing such, water infrastructure may fall into disrepair since cities underestimate what they may require to manage said infrastructure sustainably (Rural Water Supply Network 2010).

One way in which cities can address the data shortages in this regard is by implementing intelligent water management technologies. ${ }^{10}$ Intelligent water management technologies include a selection of technologies and scientific disciplines, and could assist cities in also addressing additional water service delivery challenges, such as non-revenue water and illegal water use (Steyn, 2020, p. 19, 296-299). These technologies consist of smart water systems, Information and Communication Technologies, the Internet of Things, data science, and Big Data to enable and improve water management (Steyn, 2020, p. 288-289). These technologies enable intelligent water management technologies to function at a higher capacity. As such, intelligent water

\footnotetext{
4 'Completeness' can be defined as the portion of stored data measured against the potential of being $100 \%$ complete.

5 'Uniqueness' involves that no one thing will be recorded more than once based on how it is identified.

6 'Timeliness' is described as the degree to which data represent reality from a required point in time.

7 'Data are valid if it conforms to the syntax (format, type, range) of its definition'.

8 'Accuracy' entails the extent to which data correctly describes the real-world thing or event that is being described.

9 Data 'consistency' entails the 'The absence of difference, when comparing two or more representations of a thing against a definition'.

10 Steyn argues for the use of intelligent water management technologies in cities as an avenue to address certain water services challenges, such as data insufficiencies, and towards realising the constitutional water right in South Africa. See Steyn 2020, pp. 288-300.
} 
management technologies allow for rapid response times, have the capacity to transmit data between remote locations and data processing facilities, can capture realtime information, and provide the opportunity for the interpretation of data that are presented to end-users. These technologies may also promote knowledge networking between cities as envisioned by the country's water strategies. ${ }^{11}$

The above technological interventions may be necessary, since the Master Plan firmly states that inadequate data and information caused by weak monitoring infrastructure and systems pose significant risks to both planning and decision-making, and should be addressed with great urgency through 'the formalisation of an effective national hydrological monitoring centre' (Master Plan, Volume 1 p. 43). The urgency is, arguably, driven by the fact that the lack of information from weak monitoring systems and information systems that are not maintained poses a substantial risk to attaining the goals put forward in South Africa's water legislation, policies, and strategies. ${ }^{12}$ However, it is uncertain whether the current national information systems provide data of good quality and integrity concerning cities' water service provision, and, therefore, warrants investigation.

\section{Legislative Responses}

Upon examining the relevant legal instruments, this article presents the legal responses or duties on the challenge of insufficient water service delivery-related data in cities. The legal instruments that provided duties and content to the issue of data or information in cities' water service delivery context include the Water Services Act 108 of 1997 (WSA); the Local Government: Municipal Systems Act 32 of 2000 (Systems Act); the Local Government: Municipal Finance Management Act 56 of 2003 (MFMA); the SFWS; the Framework for a Municipal Indigent Policy (2005); and the Free Basic Water Implementation Strategy 2007. This section examines these instruments.

Water services, as per the WSA, is defined as water supply and sanitation services (WSA, Sect. 1(xix)). Furthermore, various key stakeholders will be referred to throughout this discussion, as defined by the WSA. These include 'water services authorities', meaning any municipality responsible for ensuring access to water services, including district or rural councils (WSA, Sect. 1(xx)). A 'water services provider' may be understood as any person who provides water services to consumers or another water services institution, but excludes a water services intermediary (WSA, Sect. 1(xxiii)). A 'water services intermediary' is defined as any person who

\footnotetext{
11 See para 3 below for a discussion on the SFWS and knowledge networking.

12 Notably, the overarching goal of the aforementioned laws is to ensure that everyone has access to sufficient water (Constitution, Sect. 27(1)(b)). Cities or local governments have a significant role to play in achieving said goal, given their constitutional function to provide water services in the form of potable water supply systems to communities (Constitution, Schedule 4 Part B). Specifically, the minimum standard for basic water supply services is the provision of a minimum quantity of potable water of 25 $\mathrm{L}$ per person per day or $6 \mathrm{~kL}$ per household per month (Regulations Relating to Compulsory National Standards and Measures to Conserve Water 2001, Regulation 3).
} 
must provide water services to another by way of contract, where the provision of water is incidental or the primary purpose of the contract (WSA, Sect. 1(xxii)). Finally, a 'water services institution' includes water services authorities, providers, boards, and committees (WSA, Sect. 1(xxi)).

As per the WSA, water services authorities must provide a report concerning the implementation of their water service delivery plan every financial year, and at least within 4 months after the financial year. They must issue the report to the relevant Ministers, every organisation that represents municipalities, and those that have jurisdiction within the area, as well as the relevant province (WSA, Sects. 18(2) (a)-(b)). As part of its reporting duties, the municipality must publish a summary of its report (WSA, Sect. 18(3)). Both a copy of the report and the summary thereof must be available for inspection at the municipality's office and must be obtainable against payment of a nominal fee (WSA, Sects. 18(4)(a)-(b)).

As part of the principal objectives of the WSA, it provides for the duty to gather information in a national information system and distribute that information (WSA, Sect. (2(h)). The national information system is provided for in Sects. 67 to 70 of the WSA. These sections describe the establishment of a national information system (WSA, Sect. 67), the purpose of such a system (WSA, Sect. 68), and the provision of information (WSA, Sect. 69), as well as the funding of the information system (WSA, Sect. 70). The establishment of the national information system allows for the provision of processed data regarding water service provision as information to the public, and the latter system is scrutinised in this article. ${ }^{13}$

It is the responsibility of the Minister to see to the establishment of a national information system on water services, which may form a part of a larger system on water (WSA, Sects. 67(1)-(2)). The public is entitled to reasonable access to the information in such a system, and the Minister must take reasonable steps to ensure that the information provided is in an accessible format (WSA, Sects. 67(3)-(4)). The WSA provides no explanation concerning what constitutes an accessible format, but from analysing the existing national information system, one may conclude that it involves processed data that provide relevant statistics and information about water services in the country. ${ }^{14}$

The WSA stipulates somewhat ambiguously that the Minister may require any province, water services institution, or consumer to furnish information to be included in the national information system (WSA, Sect. 69). In the instance of water services institutions, it spreads the duty to provide information amongst water services authorities, water services providers, boards, and committees. However, the WSA is not specific about the information that water services institutions or cities would have to furnish upon such request.

The purpose of the national information system is to record and provide data for the monitoring, implementation, and development of national policy on water services (WSA, Sect. 68(a)). In addition, the purpose is to furnish information to water services institutions, consumers, and the public to allow them to monitor the

13 See para 4 below.

14 See para 4 below. 
performance of water services institutions, to conduct research, and for any additional lawful reason (WSA, Sects. 68(b)(i)-(iii)). The WSA recognises that it constitutes an offence if a person fails or refuses to provide information, or gives misleading or false information when required to furnish information in terms of the Act (WSA, Sect. 82(1)(e)). This is valuable because it provides for both transparency and accountability in the water services sector, especially where water service provision is concerned.

In the instance that water services are delivered by water services providers in a municipality, the water services provider may be obliged to provide information pertaining to the provision of water services, as may be reasonably requested by the water services authority in question, the relevant province, the Minister, a consumer, or a potential consumer (WSA, Sect. 23). A somewhat similar duty is placed on water services committees in the instance that they are required by the Minister or any authorised person to provide information concerning the affairs and financial position of the water services committee, including access to accounts, books, documents, and other assets of the water services committee that may be required (WSA, Sects. 59(1)(a)-(b)). This is often the case when the Minister or water services authority appoints a person to investigate the financial position and affairs of the water services committee (WSA, Sect. 59(2)). Likewise, water services institutions must provide the information required by the Minister to fulfil the performance monitoring duties envisioned in Sect. 62(1) of the WSA.

Generally, the Systems Act determines the core principles, procedures, and framework to allow municipalities to uplift their community economically and socially through guaranteeing affordable and universal access to basic services. The Systems Act allows for provincial monitoring of municipalities, as well as national monitoring and standard setting (Systems Act, Sects. 105-108). ${ }^{15}$ This includes the furnishing of information (Systems Act, Sect. 107). Provincial monitoring of municipalities is essential insofar it allows for the Member of the Executive Council for local government to assess whether a municipality cannot, or does not, fulfil a statutory obligation binding on that municipality. The latter includes whether fraud, corruption, maladministration, or any other serious malpractice is occurring or has occurred in the municipality of that province (Systems Act, Sects. 105-106). The Systems Act, similar to the WSA, makes provision for the Minister to request information from municipalities concerning the affairs of the municipalities as set out by notice in the Government Gazette (Systems Act, Sect. 107). The Minister may do this at regular intervals, or within a specified period.

Municipal administrations must give members of the local community accurate and complete information on the level and standard of municipal services that they may receive (Systems Act, Sect. 6(2)(e)). The above duty extends to informing the community of how the municipality is managed, and the costs involved, as well as the persons in charge (Systems Act, Sect. 6(2)(f)). These duties also relate to essential elements of ensuring that cities have sufficient data, namely that the data

\footnotetext{
15 Chapter 10 of the Systems Act generally deals with provincial and national monitoring and standard setting.
} 
or information can inform cities' decision-making, and that communities can stay informed of their entitlements (including what is being done in the municipality to take care of their needs). This is of particular relevance to water service provision, since these duties allow communities to hold municipal administrations accountable if they do not receive the basic level of water supply to which they are entitled.

The MFMA provides for the sustainable management of the financial affairs of municipalities and any other institutions operating in the local government sphere (MFMA, preamble). Under reports and reportable matters, the MFMA provides for access to information by determining the information to be placed on the websites of municipalities (MFMA, Sect. 75). This section states that the accounting officer of a municipality must place on the website of the municipality certain documents, for instance all budget-related policies; the annual report; performance agreements; all service delivery agreements; an information statement stating assets over a prescribed value that have been disposed of in the previous quarter; public-private partnership agreements; and all quarterly reports tabled in the council; as well as any other documents that must be made available on the website in terms of the MFMA, or any other applicable legislation required (MFMA, Sects. 75(1)(a)-(1)). The MFMA prescribes that these documents must be placed on the website of the municipality no more than 5 days after the tabling thereof by the council, or on the date on which it must be made public, whichever date occurs first (MFMA, Sect. 75(2)).

In terms of the Framework for a Municipal Indigent Policy (2005), the only duty directly relating to municipalities is that the location of consumer units (defined as groups of people who live on the same property or in a dwelling or dwellings in informal or rural areas) including served and un-served units must be identified on a Geographic Information System (GIS) that should be controlled by the municipality, and which must link to a national system (Framework for a Municipal Indigent Policy (2005), p. 26, 32). While not expressed as a duty, the Framework states that the national monitoring system in question should link to existing data management and planning systems applied by municipalities (Framework for a Municipal Indigent Policy (2005), p. 26). This implies that municipalities must both have these systems in place and ensure that they are compatible with national systems. The Framework also states that, in terms of information gathering, specifically for maintaining access to information, all information will be collected through annual municipal services surveys which will be run by Statistics South Africa (Framework for a Municipal Indigent Policy (2005), p. 26). Thus, the collection of information will be managed by national means, but cities will, at least to some extent, be involved.

The Free Basic Water Implementation Strategy of 2007, on the other hand, clearly expresses the duty for water services authorities to provide regular feedback on the implementation of free basic water to the contemporaneous Department of Water Affairs and Forestry (and the now DWS) (see Free Basic Water Implementation Strategy 2007, p. 29). This information will be used to monitor and evaluate the implementation process, which will provide a means to assess the water access situation at the local level (Free Basic Water Implementation Strategy 2007, p. 29). This is a crucial requirement, since the Strategy stipulates that one of the challenges municipalities face in the provision of free basic services is poor monitoring and 
duplications in the information requirements from the national government (Free Basic Water Implementation Strategy 2007, p. 4).

However, since the Strategy expresses that the planning and implementation requirements on municipalities pertaining to the free basic water policy are quite substantial, the national government is required to provide support in various areas of the implementation process, including providing information and planning tools, and monitor the progress of the policy (Free Basic Water Implementation Strategy 2007, p. 29). As for the latter-mentioned issue, the Strategy states that the national government will monitor the progress of the provision of free basic water via the water services development plans of municipalities, as well as through National Treasury's financial monitoring (Free Basic Water Implementation Strategy 2007, p. 29). Thus, municipalities must collect data and information on the implementation of the free basic water policy in their area and report thereon in their water services development plans.

The above analysis serves to flag a number of concerns. Firstly, and perhaps the most worrying of all, is that there is a clear gap in the law concerning the collection of data and information by cities on the water services they provide. Specifically, the law requires cities to either furnish, supply, or provide information to certain stakeholders for inclusion in national information systems, but there is no clarity as to what information such a request would entail. Furthermore, no actual duty exists to collect the data or information on their water services provision. While it may be reasonable to argue that such a duty can be inferred, or that it is implied, the usefulness of the duty to furnish, supply, or provide information is questionable, especially since there is no clear indication of what information cities would need to provide. Given cities' unique position as water service providers, it is both puzzling and worrying that cities are not required adequately by the law to collect data and information on the water services they provide. Arguably, in the absence of clear legal guidelines requiring the collection or monitoring of water services provision, it is doubtful whether cities would, or could be expected to, fulfil a vague obligation of this nature.

Secondly, the above analysis shows that it remains the DWS' duty to collect data, and that water services authorities provide optional support to the Department. This support is in the form of furnishing or supplying information to the DWS. At no point does the legislation provide for the collection of data by cities toward assisting them in, for instance, decision-making. This contrasts with newer water service provision plans and strategies wherein the essential role and benefit of the collection of data, and the continuous monitoring of data, are emphasised (see, for instance, the Master Plan).

Instrumental to this discussion on the insufficiency of data in cities is the focus of 'knowledge networking' in the SFWS. As per this framework, the purpose of 'knowledge networking' is '...to ensure that the wealth of water services information and knowledge is accessible, disseminated and applied within the sector. This entails a range of activities from information management to peer learning and lesson sharing through a variety of mechanisms, such as internet-based knowledge hubs, e-mail-based newsgroups, forums, conferences, workshops' (SFWS, p. 57). The SFWS states that the goal of this knowledge network is that all sector players 
should both be able to contribute and access appropriate knowledge from knowledge networks (SFWS, p. 57). Thus, the aim is to facilitate informed decision-making within the water sector, and capacity building, specifically within water services institutions (SFWS, p. 57). The SFWS determines that the approach to be followed in this regard is to build on the capital and potential of existing knowledge management centres, as well as optimise their contributions for the ultimate good of the water sector (SFWS, p. 57).

Consequently, water services knowledge and information will be included in existing and developing local government knowledge networks (SFWS, p. 57). Theoretically, this should allow for effective demand-driven mechanisms aimed at sharing knowledge and, coincidentally, support the transfer of so-called best practices across the sector (SFWS, p. 57). As such, the SFWS may, arguably, be the first instance in which data or information are deemed necessary where cities are concerned for issues such as decision-making, rather than merely for monitoring and recording.

The SFWS does make provision for monitoring and information management (SFWS, p. 59). It deems relevant, timely, and reliable information necessary for rendering the support given more appropriate and effective by informing the nature and extent of the support needed (SFWS, pp. 59-61). Likewise, monitoring is required to identify instances where interventions are needed to protect the public interest (SFWS, pp. 59-61).

The SFWS provides certain principles pertaining to monitoring and information management, such as 'scope and comprehensiveness'. The latter principles dictate that developing a comprehensive, all-encompassing national management and information system would be a mistake, since such ambition may cause the undoing of those systems (SFWS, p. 59). This is so since it may result in the development of large, complex, and expensive information systems that may have only partial datasets. These datasets may fail in terms of the original objectives set (SFWS, p. 59). It is therefore that the SFWS suggests the development of fit-for-purpose monitoring and information systems, which are likely to be cost-effective and successful in achieving its goals (SFWS, p. 60). Fit-for-purpose systems are those that are designed with specific objectives in mind, including a statement outlining why and how the data must be collected and used and for what purposes (SFWS, p. 60).

For the sake of brevity, it is pertinent to mention that the recommendations of the SFWS are explored in further detail in the NWRS. The NWRS indicates that both the collection and monitoring of data in the water sector will affect the accuracy of water resource status assessments, as well as subsequently determining the extent of the country's water problems (NWRS, p. iv). Proper data collection and monitoring are said to be capable of vastly improving planning and policy formulation processes (NWRS, p. iv).

Although the Master Plan emphasises the need for, and the role of, data and information in the water sector, it is aligned with the current legislative vision and, therefore, focuses on the role of the DWS in this regard. There is a disparity between the water service provision-related legislation and certain strategies that were developed more recently. Though this article will now scrutinise the national information system envisioned by the country's water laws, it suffices to say that the current 
legal duties on cities to collect data are non-existent and that given the continuous so-called weak monitoring system in the water sector, there is room for legislative development in this instance.

\section{The Duty on Cities to Furnish Information to National Information Systems}

The DWS initiated the development of the National Integrated Water Information System (hereafter NIWIS) based on its duty to establish a national information system (WSA, Sects. 68-67; DWS, 2021a; Master Plan, Volume 1 p. 43). The latter system is an integrator of current DWS information systems and programmes aimed at providing data to sector decision-makers (Master Plan, Volume 1 p. 43). The NIWIS provides information products via 'dashboards' to facilitate efficient reporting and analysis throughout the country's water value chain (DWS, 2020).

In the final months of 2020, NIWIS was updated to include more 'dashboards' than previously available. These dashboards include Climate and Weather, Disaster Management, Infrastructure, Monitoring Networks, Water Ecosystems, Water Quality, Water Resources Management, Water Quantity, Water Services, and Water Tariffs. Given the article focuses on water service provision-related data, this section will analyse the relevant dashboard and information only.

The water services dashboard on the NIWIS provides sections for Access to Water Infrastructure Delivered, Water Supply Reliability, and Non-revenue Water, amongst others (DWS, 2021a, 2021b, 2021c). The information section (which is almost the same for all aforementioned sections) of the Access to Water Infrastructure Delivered section states that the data are provided by 'Water Services' and is 'updated monthly'. However, at the time of the writing of this article in March 2021, the Access to Water Infrastructure Delivered section provides that the 'latest data available' is from December 2020 (DWS, 2021a). The information section also states that the section 'indicates the percentage of population and households that have access to drinking water' (DWS, 2021a). The argument seems to be that once households have been provided with water infrastructure, they automatically have access to water. This is, perhaps, a significant flaw in logic, as even when households are provided with working water infrastructure, the sustainability thereof is not guaranteed (Allen and Lemme 2016). In other words, it is uncertain for how long infrastructure may remain in working order, since it is often susceptible to breakages or malfunction.

Another key assumption indicated on this dashboard is that the information represents households or water users that have been given access to, at the minimum, Reconstruction and Development Programme-level water supply. ${ }^{16}$ No information or consideration of scheme functionality (thus, whether the scheme is still completely functional with no interruptions) is offered. Disregard for the sustainability of water service delivery is a major challenge in South African

16 This entails $25 \mathrm{~L}$ of water per person, per day. 
cities (Allen and Lemme, 2016). Arguably, the proper management of water scheme functionality should include the monitoring thereof, which could provide immensely valuable data for cities to explore.

Whether the water infrastructure provided to persons is still in working order is addressed by another section on the NIWIS, namely the 'water supply reliability' subdivision (DWS, 2021b), but it is also not without issues. This dashboard aims to provide data on the functional access to basic water supply infrastructure, yet states that it is only updated once a year in April (DWS, 2021b). Currently, the only available data on this section are from July 2020 (DWS, 2021b). Since no continuous monitoring system is in place, it is conceded that it does not provide an accurate depiction of the state of functional water supply in the country. This is because, as mentioned in part two above, accuracy in terms of data entails the extent to which data correctly describes the real-world thing or event that is being described. As with the other sections on the Water Services dashboard, the information section states that, in terms of the status of the data, 'data are continuously updated; the data set(s) supplied are already historical on the day of supply' (DWS, 2021b). It provides no evidence that there is some system in place that continuously monitors, for instance, water supply reliability. The dashboard does indicate that NIWIS may at any time request updated information (DWS, 2021b), but this information is not immediately made publicly available. Considering the purpose of the national system of information set out in the WSA, the outdated data provided on the NIWIS do not allow for accurately monitoring the performance of the water services sector (WSA, Sects. 68(b)(i)-(iii)). It is thus that the Master Plan advocates for the development of improved and modernised information systems to safeguard access to reliable data, information, and knowledge concerning the status of the country's water resources and supply (Master Plan, Volume 1, pp. 43-44).

The data and information used on this, and most other dashboards on the NIWIS, are said to have originated from the NWSKS, which is founded on data from the results of Statistics South Africa's censuses and General Household Surveys (DWS, 2021b). Furthermore, it is said to be aligned with and updated by the DWS' 'macro planning data' (DWS, 2021b). NIWIS states it is also extracted via 'macro planning processes and procedures' directly from the NWSKS (DWS, 2021b). There is no clear origin of the so-called macro planning data given the circular nature of the information provided. Moreover, there is no indication that local governments were requested to provide any information. This brings into question whether the Minister of the DWS adequately utilises its legislative discretion to request information from local governments for the NIWIS.

Given that the above data are mainly sourced by national means (e.g. Statistics South Africa censuses and General Household Surveys) (DWS, 2020), it is conceivable that an opportunity exists for the law to enable local governments to do more to gather updated and accurate data. This includes keeping accurate and up to date municipal records and utilising innovative means to collect the relevant data, such as continuous monitoring systems. The latter could allow for a more accurate national depiction of water provision in the country and may go a long way in assisting water conservation and demand management efforts. 
The NWSKS hosts national, provincial, and local level information concerning a variety of themes, such as demography; access to basic services (based on access to water infrastructure); water services programmes; water quality management; institutional effectiveness; water conservation and demand management; finances; protest hotspots; census results; and water board-related data (NWSKS, 2020). Although the aforementioned presents itself as an impressive feat, as will be discussed below, some serious issues come to light when analysing the information on the NWSKS and relaying it back to what is provided on the NIWIS. It affirms the fact that local governments across South Africa have a serious challenge to overcome because they have insufficient data on the water services they provide (DWS, 2020).

As mentioned above, the accuracy and timeliness of data are essential dimensions of data quality (DAMA UK Working Group, 2013), and data that are not current may be viewed as outdated and inaccurate. By employing the NWSKS randomly to provide data at a local level on the City of Matlosana in the North-West province, the information provided on the themes is immensely inconsistent regarding specifically the date on which the data or information were recorded (NWSKS, 2021a). There are no data provided for the current year, 2021, and the only data provided from 2020 are that on the demography, access to basic services, and water quality management in this municipality (NWSKS, 2021a). While it is not stipulated on the NWSKS, it is possible that the availability of data for both 2020 and 2021 may have been impacted by the ongoing COVID-19 pandemic. However, themes such as water board-related information and water demand management date back as far as 2014 and 2011/2012, respectively (NWSKS, 2021a).

The latter-mentioned date on water demand management is especially troubling. This theme sets out information on the state of non-revenue water and water losses (NWSKS, 2021a). As per the NWSKS, information on municipal non-revenue water and water losses are founded on 'municipal inputs where available and DWS estimates where not available' (NWSKS, 2021a). The last nationwide investigation into non-revenue water was conducted in 2012 (see McKenzie et al., 2012), which coincides with the date of the data utilised on the NWSKS. Hence, firstly, as per the NWSKS at least, current nationwide estimates as to non-revenue water are still based on ancient data and firmly underscore the fact that cities are potentially making decisions and managing water resources founded on outdated and insufficient data. Secondly, the NWSKS acknowledges using DWS 'estimates' for providing the data concerning non-revenue water, yet does not provide the source of this data (NWSKS, 2021a). The accuracy of these estimates, and thus the integrity of the entire database, is questionable.

Thirdly, the non-revenue water section on the NIWIS states that limited assessments on the matter were conducted until 2012, but that from 2014 the assessments will be conducted via the 'No Drop' process, set to take place every second year (DWS, 2021c). While the NIWIS only provides for the assessment data of 2017 (that it reportedly obtained from the NWSKS), the NWSKS' information on the 'No Drop' programme covers the years 2008-2017 (NWSKS, 2021b). Again, the integrity of these statistics is disputable, given that the values on which they are based are identical for each province for the 6 years from 2012 to 2017. Thus, the North-West 
province, for instance, has a reported non-revenue water rate of $41.2 \%$ for the years 2012-2017, whereas the Gauteng province reportedly remained at $34.7 \%$ for the same years, and so forth (NWSKS, 2021b).

Furthermore, this information offers no guarantee of reliability, since, as per the 'data used to generate the information' section on this site, it is provided that 'Where information is not available other sources of information such as the All Towns Studies are used and failing this default values are generated per municipal category. At any time, about half of municipalities can provide information, but this equates to about $75 \%$ of water consumed' (DWS, 2021c). From this, one may deduce that socalled default values are generated without providing the data on which these values are based. This relates to the integrity of the data, and that to verify the integrity of data, one requires the availability of 'metadata'. Metadata refers to the descriptions of the context, content, and structure of certain information objects, such as research data, at any level of aggregation (e.g. a single data item, many data items, or entire databases) (Kleppner, 2010). Even though data that are used to derive findings or information, draw conclusions, or build models may usually undergo various changes during processing, archiving, or distribution, it cannot be accurately interpreted or utilised when lacking understanding of the processing undergone (Kleppner, 2010). It is normally not possible to judge the integrity of data that have been processed without access to the metadata (Kleppner, 2010).

While data estimation is not a questionable practice (PennState Elberly College of Science, 2018), ${ }^{17}$ it becomes problematic where no information or metadata are available concerning how these estimations were made or the data used to do so. In such instances, one must be wary of crossing the Rubicon into merely fabricating information or data. Therefore, high standards of openness and transparency are necessary to ensure the integrity of data, and ultimately, the usability thereof (Kleppner, 2010).

The above deliberation is, worryingly, underscored by cautionary messages, which are displayed on most of the dashboards on NIWIS regarding the data it provides. As mentioned above ${ }^{18}$ it constitutes an offence if a person gives misleading or false information when required to furnish information by the DWS (WSA Sect. 82(1)(e)). Thus, significant value is placed on the correctness of information in this regard. However, the information section pertaining to water services on the NIWIS states that as for the quality of the data: "All data is supplied with no expressed or implied warranty as to its suitability for purpose, accuracy or completeness' (DWS, 2021a). The latter aspects of accuracy and completeness are of relevance here since both potentially amount to misleading or false information, yet on this occasion, it is provided by the DWS.

With no certainty as to the quality, completeness, or accuracy of data, it may be viewed as potentially unusable, especially where the rendering of data into information via certain algorithms is concerned. Insufficient data in terms of quality and accuracy may lead to a variety of issues upon its implementation, such as wider

17 Data estimation is an accepted statistical practice.

18 See para 3 above. 
margins of error and unusable machine learning tools (Redman, 2018), ${ }^{19}$ and may even lead to many types of bias upon the use of such data for Artificial Intelligence (AI) algorithms (Williams et al., 2018). ${ }^{20}$ This leads one to question the ultimate practicality of the database, particularly when the computer science concept of 'garbage in garbage out' is given thought. This concept expresses the idea that, in computing and many other spheres, data that are incorrect or of poor quality will always render faulty output (Oxford Reference, 2021).

From the above deliberation, one may argue that both NIWIS and the NWSKS have been developed by the DWS with questionable levels of success. The DWS is currently developing many water services systems. These include the Integrated Regulatory Information System, the Water Sector Policy Database, and the Technical Knowledge Centre. These developments, along with the NWSKS, debatably, present great promise for the advancement of the availability of data concerning water services provision. However, arguably, for databases such as the NIWIS and NWSKS to succeed and to be purposeful, cities need to take an active role in the collection of water services-related data. This may also contribute significantly to solving the challenge of insufficient water service delivery-related data in cities, and may strengthen cities' ability to provide water services to communities adequately.

\section{Conclusion}

In terms of the key question this article set out to answer, it is conceded that legal responses and duties exist on cities to furnish information to, for example, the DWS, communities, and other stakeholders, particularly for this information to be included in the national information systems. However, no duty exists for cities to collect the data or information that they require for decision-making, or are regularly required to provide. The absence of an explicit duty on cities to collect data, paired with the ambiguity resulting from the WSA's lack of specificity regarding the information that cities would have to furnish, means it is unlikely that cities would be able to fulfil such a vague obligation. The lack of and outdated data on the NIWIS and the NWSKS evidences this. There is also a deficiency in terms of regulations pertaining to, for instance, how data should be collected, including guidance on maintaining and ensuring the quality and integrity of data. Thus, while current plans and strategies emphasise that data and information are necessary for, amongst other issues, proper decision-making, cities struggle with the challenge of insufficient data on the water services they provide due to weak or absent monitoring systems (Parliamentary Monitoring Group 2017).

\footnotetext{
19 Machine learning is the process whereby systems learn from data, such as training a system to make certain decisions based on the data it is provided with. In so doing, the system updates its learning, and hopefully develops improved decision-making abilities as it is provided with more data.

20 Bias is known as unfair preference, and entails the systematic discrimination against particular groups or individuals based on certain inappropriately used traits or characteristics, such as race, gender, and sexual orientation. Bias in AI occurs from the data that are fed to the algorithm involved. Bias in this regard may be either intentional or unintentional, and is often unpredictable.
} 
As mentioned above, the Minister of the DWS is responsible for the collection of data, and for ensuring the existence of a national information system on water services (WSA, Sects. 67(1), 67(4), 68, and 69). The DWS fulfils its mandate through the establishment and maintenance of the NIWIS and the NWSKS. However, the above analysis of the NIWIS and the NWSKS revealed that there are numerous and significant issues on these databases, especially concerning the quality, integrity, and timeliness of the data. The WSA does state that water services authorities must provide the Minister with data upon request, but there is no clarity concerning this process, and how frequently it is required of water services authorities. Moreover, because of the absence of a dedicated duty on cities to collect the necessary water service delivery data, issues such as outdated data may persist. This raises the question of whether the current legal framework which centralises the collection of data is adequate.

Since cities are often limited in terms of capacity, and to avoid fragmentation, the DWS should remain primarily responsible for the management of water services-related data. However, given the unique position of cities concerning the provision of water services, and the need for complete and reliable data, the law should emphasise cities' role in the collection of data. Regulations should, ideally, guide cities on the collection of relevant water services data, including guidelines pertaining to the quality and integrity of data.

Acknowledgements I am extremely grateful to Professor Anél du Plessis, Ms Maricélle Botes, Ms Melandri Steenkamp, and Ms Johandri Wright for their valuable comments and suggestions.

Author Contribution Nicolene Steyn is the sole author.

Funding This paper was funded by the National Research Foundation of South Africa (NRF) (Grant No. 115581). All viewpoints and errors remain the author's own.

Availability of Data and Material This paper is based on research that was conducted for the author's PhD thesis (titled: The Realisation of the Constitutional Water Right in South African Cities through Intelligent Water Management Technologies) at the North-West University, Potchefstroom, South Africa. The author passed the PhD in Law and Development on 2021-03-03.

Code Availability Not applicable.

\section{Declarations}

Conflict of interest The author declares no competing interests.

\section{References}

Adams, S. (2019, 4 June). Data-driven decision-making for water security. Water Online. Accessed 13 February, 2021, at http://www.waterafrica.co.za/index.php/news-events/news/447-data-driven-decis ion-making-for-water-security

Allen, E., \& Lemme, K. S. (2016). A model to end water poverty through sustainable service delivery. American Water Works Association, 108(6), 45-50. https://doi.org/10.5942/jawwa.2016.108.0095 
Bauer, G. K. (2020). Digital solutions to improve basic service provision to the urban poor. Field Actions Science Reports, 22, 116-124.

Bibri, S. E. (2018). Smart Sustainable Cities of the Future. Springer.

DAMA UK Working Group (2013). The six primary dimensions for data quality assessment: Defining data quality dimensions. DAMA UK Working Group. https://silo.tips/download/thesix-primarydimensions-for-data-quality-assessment. Accessed 16 Jan 2021.

Department of Water Affairs (2013). National Water Resource Strategy: Water for an Equitable and Sustainable Future. Department of Water Affairs. https://cer.org.za/wpcontent/uploads/2013/07/ NWRS2-Final-email-version.pdf. Accessed 13 Jan 2021.

Department of Water Affairs and Forestry (2007). Free Basic Water Implementation Strategy 2007: Consolidating and Maintaining. Department of Water Affairs and Forestry. https:/www.gov.za/sites/ default/files/gcis_document/201409/fbw-strategy-version-4-final-20070402-mk0.pdf. Accessed 14 Jan 2021.

Dos Santos, S. (2017). Urban growth and water access in sub-Saharan Africa: Progress, challenges, and emerging research directions. Science of the Total Environment, 607-608, 497-508. https://doi.org/ 10.1016/j.scitotenv.2017.06.157.

DWS (2020a). National Water and Sanitation Master Plan. DWS. https://www.gov.za/sites/default/files/ gcis_document/201911/national-water-and-sanitation-master-plandf.pdf. Accessed 13 Jan 2021.

DWS (2020). National Integrated Water Information System. DWS. Accessed 15 February, 2021, at https://www.dws.gov.za/niwis2/

DWS (2021a). National Integrated Water Information System: Access to Water Infrastructure Delivered. DWS. Accessed 16 February, 2021, at https://www.dws.gov.za/niwis2/AccessToWaterID

DWS (2021b). National Integrated Water Information System: Water Supply Reliability. DWS. Accessed 16 February, 2021, at https://www.dws.gov.za/niwis2/WaterSupplyReliability

DWS (2021c). National Integrated Water Information System: Non-Revenue Water. DWS. Accessed 17 February, 2021, at https://www.dws.gov.za/niwis2/ws_nrw

Kleppner, D. (2010). Ensuring the Integrity, Accessibility, and Stewardship of Research Data in the Digital Age. Purdue University. https://docs.lib.purdue.edu/cgi/viewcontent.cgi?article=1023\&context= iatul2010. Accessed 13 Feb 2021.

Masindi, V., \& Dunker, L.C. (2016). State of Water and Sanitation in South Africa. CSIR Built Environment. https://www.researchgate.net/publication/311451788_State_of_Water_and_Sanitation_in_ South_Africa. Accessed 15 Nov 2021.

McKenzie, R., Siqalaba, Z.N., \& Wegelin, W.A. (2012). State of Non-Revenue Water in South Africa (2012). Water Research Commission. http://www.wrc.org.za/wp-content/uploads/mdocs/TT\% 20522-12.pdf. Accessed 13 Jan 2021.

NWSKS (2020). National Water Services Knowledge System. NWSKS. Accessed 9 December, 2020, at http://ws.dwa.gov.za/wsks/

NWSKS (2021a). National Water Services Knowledge System: WSA: City of Matlosana [NW403]. NWSKS. Accessed 9 December, 2020, at http://ws.dwa.gov.za/wsks/default.aspx?SubjectAre aID $=-1$

NWSKS (2021b). National Water Services Knowledge System: Non Revenue No Drop (NDRP). Accessed 18 February, 2021, at http://ws.dwa.gov.za/ndrp/

Oxford Reference (2021). Garbage in garbage out. Accessed 18 March, 2021, at https://www.oxfordreference.com/view/https://doi.org/10.1093/oi/authority.20110803095842747\#

Parliamentary Monitoring Group (2017). Water Master Plan; Water and Sanitation Bill; Economic Regulator for Water: DWS progress report; with Minister. PMG. https://pmg.org.za/committee-meeting/ 25442/. Accessed 12 Mar 2021.

PennState Elberly College of Science (2018). Statistical Inference and Estimation. Accessed 15 March, 2021, at https://online.stat.psu.edu/stat504/lesson/statistical-inference-and-estimation

Redman, T.C. (2018, 2 April). If Your Data Is Bad, Your Machine Learning Tools Are Useless. Accessed 18 March, 2021, at https://hbr.org/2018/04/if-your-data-is-bad-your-machine-learning-tools-areuseless

Rural Water Supply Network (2010). Myths of the Rural Water Supply Sector, Perspectives No 4. Rural Water Supply Network. https://www.rural-water-supply.net/_ressources/documents/default/226.pdf. Accessed 13 Feb 2021.

Steyn, N.R. (2020). The realisation of the constitutional water right in South African cities through intelligent water management technologies. PhD in Law and Development. North-West University, 1-350. http://hdl.handle.net/10394/37564 
Thakuriah, P., Tilahun, N., \& Zellner M. (eds). (2017). Seeing Cities Through Big Data. Springer

Water Research Commission (2019a). A Framework for Monitoring and Reporting Water Supply Goals and Targets (2016-2030). Water Research Commission. http://www.wrc.org.za/wp-content/uploads/ mdocs/2588\%20Vol\%202.pdf. Accessed 15 Nov 2021.

Water Research Commission (2019b). Responding to New National and International Water Supply and Sanitation Monitoring and Evaluation Obligations. Water Research Commission. http://www.wrc. org.za/wp-content/uploads/mdocs/2588\%20Vol\%201.pdf. Accessed 15 Nov 2021.

Williams, B.A., Brooks, C.F., \& Shmargad, Y. (2018). How algorithms discriminate based on data they lack: Challenges, solutions, and policy implications. Journal of Information Policy, 8, 78 - 115. https://doi-org.nwulib.nwu.ac.za/https://doi.org/10.5325/jinfopoli.8.2018.0078

Publisher's Note Springer Nature remains neutral with regard to jurisdictional claims in published maps and institutional affiliations. 